\title{
ASSESSING MARKET DEMAND FOR WEB PROGRAMMING LANGUAGES/TECHNOLOGIES
}

\author{
David Smith, Indiana University of Pennsylvania, david.smith@iup.edu \\ Azad Ali, Indiana University of Pennsylvania azad.ali@iup.edu
}

\begin{abstract}
This paper assesses the market demand for the different programming languages and technologies covered in web programming courses. It will use the assessment of the market demand data to suggest content and technologies to teach at a web programming course at the department of Computer Science (COSC) at a university located in Western Pennsylvania.

A faculty member at the Computer Science department at Indiana University of Pennsylvania (IUP) has been collecting data about job demand for a number of languages and technologies used in Computer Science courses. In this paper we share the data gathered that is related to web programming, analysis of the data and implications for curriculum content in web programming courses. In order the give background information about this study, the paper begins by discussing the factors that influence the decision for selecting content to teach in web programming courses. It then explains that market demand is a factor that needs to be considered in selecting the same content for web programming courses and provide analysis for the collected data. The study last shares the experience of one faculty that is collecting the data and analyzing them to determine content and technologies to teach in his web programming course.
\end{abstract}

Keywords: Web programming course content; Web programming curriculum, Courses in web design, Pedagogy of web design course, Content of web programming courses

\section{INTRODUCTION}

Compared to teaching a standalone programming language (i.e., C++, or Java), web programming requires a programmer to know a group of related technologies. Teaching all these technologies in detail would require multiple additional courses. Students in a CS program usually do not have enough extra time to take several additional courses. When developing web programming courses, we need to identify what web technologies must be taught, and then decide what and how many web programming courses should be added to the curriculum so that students can use their limited schedule to take the courses to learn and master the necessary web programming skills. [22, p. 69].

This study is a continuation of a paper that the authors have recently published about analysis of the demand for programming jobs using web data mining techniques. In our previous published paper [17], we explained about using web data mining to assess the market demand for standard programming languages (Such as Java, C, Visual Basic, COBOL and others). In this study we will focus on web programming languages and technologies. Although the use of the word "programming" in both web programming and standard programming may give the impression that the content may be similar. However, the factors that influence the selection of content for web programming courses are different from those that select contents for standard programming courses [18] [23]. Thus this study intends to fill this gap and provide suggestions for content to teach in web programming courses based on literature review and analysis of market demand for such jobs.

Our goal from this study is twofold: First to assess the market demand for web programming and technologies jobs and second to provide suggestions for content and technologies to teach in our web programming course. The remainder on the paper is divided into the following sections:

- The paper begins by explaining about web programming courses and the different paradigms and technologies involved in teaching them.

- The second section discusses the benefits that can be gained from assessing market demand for technology jobs in particular in general and web programming jobs in particular 
- The third section explains about the data collected by the author regarding trends of web programming/technologies and the analysis of the same data

- A conclusion/recommendation will be introduced by the authors at the end of this paper based on the literature review and the assessment of the market demand for web programming jobs.

\section{WEB PROGRAMMING AND TECHNOLOGIES}

The term "web programming" may give the impression that what is applied or taught in a standard programming course is followed the same in web programming courses. It may convey understanding that teaching web programming is closely similar to teaching standalone or general programming courses where one programming language may be used/taught for an entire course. However, this impression is only partially correct in that there is some programming used within both contexts (the teaching of web programming and programming). But web programming encompasses more than just the use of a programming language; it includes the selection of multiple different paradigms, technologies and platforms [3] [20] [21].

This section explains about three factors that typically affect the selection of topics (technologies) to teach in web programming (design) courses. Although the phrase "web design" may give different meaning than the term "web programming" at some times [19], but we are going to use the two terms in this paper synonymously - that is designing web pages using web programming languages and related technologies.

\section{Web Design Paradigms}

The great diversity of paradigms that underpin the Web's functionality presents a challenge to the designer and teacher of any topic covering web technology. .... Students need sufficient depth of knowledge in several key areas in order to be able to become proficient in the relevant techniques. Notwithstanding, breadth of coverage is still required given the plethora of technologies associated with the web [20, p. 27].

Ali and Mensch [1] discussed the contrasting paradigms of web design and their application to the teaching of web design courses. They tackled the issue of teaching web design from the following three different contrasting paradigms:

- Using Code versus Software Tools

- Static, Dynamic, and Interactive

- Server Side versus Client Side

Although the three paradigms contrast each other and may affect content of courses that teach them, but this paper focuses on web programming and related technology. Therefore, the only paradigm that is applicable to this study is about client versus server side thus these two contrasting paradigms are explained first in this section. An explanation of the client versus server side paradigms is discussed here.

The terms "Server Side" and "client side" often referred to discussing web pages in general. However, these two terms normally refer to the dissimilar roles within the web architecture. These terms also reference different sets of language code and interfaces associated with a specific web page. Gosselin [7] explained the difference between client side and server side technologies as:

Client-Side scripting refers to a scripting language that runs on a local browser (on the client-tier) instead of on a web server (on the processing tier) (p.35).

Server-side scripting refers to a scripting language that is executed from a Web server. One of the primary reasons for using a server-side scripting language is to develop interactive web sites that communicate with a database (p. 36).

The available options within the client and server side may directly affect the selection of technologies. Wang [22] describes technologies such as ASP, PHP, or ColdFusion as "designated" for server side web development. Gosselin [7] on the other hand was more specific about the technologies involved and explained that client side web pages are those developed using HTML and Javascript languages. 
While the client side technology seems to standardize around HTML, CSS and JavaScript, there is no similar standardization of server side programming languages. Stepp, Miller and Kirst [18] suggested six common programming languages that are used in the industry and being taught at web programming courses in computer science programs. These languages include PHP, Java/JSP, Perl/CGI, Ruby on Rails, Microsoft .NET, Python/others. Although these languages may be used for purposes other than the web design, their use for web application is extensive as well [8].

Comparison of proper application of these server side technologies and their appropriate application is ongoing as new web technologies continue to be developed. Holkner and Harland [11] for example noted that Python is a language more suited for dynamic application and it is not susceptible to static analysis. Trent et al. [19] compared the performance of PHP and JSP and concluded that although both are used at web server application but PHP is commonly used for front-end interface as well. Serrano et al. [15] on the other hand introduced a different language called HOP and noted that it is designed for interactive web applications and it separates logic and graphical user interface. The offer mentioned discussion highlight the need for educators to study the applicability of the selected technology when designing content for their web programming courses.

\section{The Multitude of Web Design Technologies}

The number of technologies that are used to design web pages has increased significantly as compared to the tools that were used initially to create such web pages. Initial efforts to design web pages were limited to using a simple text editing tool (like notepad) and a browser (like Internet Explorer). However this simple list has been extended to a longer record of software tools [15] that are full of acronyms and that are sometimes hard to sift through and distinguish. Bardzell [2] provided a brief list of these acronym-rich software tools that are used for designing web pages such as: HTML, CSS, Macromedia, Coldfusion, ASP, SQL, XHTML, DHTML, XML, ADO, CDO, JavaScript, Flash, PHP, Java, .NET, XSLT, WML, and WSDL.

These technologies represent just one snapshot of what is included in web technologies. If we add technologies for mobile devices and the interfaces with various technologies, the list grows much longer. The point to be driven from this is; how much and what of these technologies can be taught at a given web programming course. Although the number of these technologies seems large (and sometimes overwhelming) some of these technologies are grouped together into what is termed as "web platforms".

The implication of this large number of technologies on course design is enormous and could be subject to many constraints. The most notable constraints are the compatibility among the selected technologies. Although they may seem to work seamlessly, but there is also intermediate technologies involved as well. The best can be described in the groups of web platforms.

\section{Web Platforms}

Web platform refers to the combination of technologies that work together to perform the complete task of web functions. Two dominant competitors during mid-2000's have been .Net from Microsoft and J2EE from Sun Microsystems, (recently acquired by Oracle). .Net encompasses a number of programing languages including C\# and Visual Basic, ASP.Net for HTML template services, and ActiveX Data Object for databases access. J2EE or now Java EE includes Java as the programing language, JSP for HTML template services, object relational mapping API's, and Java Server Faces (JSF) as a framework providing the Model View Controller (MVC) architecture. Alternatives to the JSF framework are Struts from Apache and Spring Framework from Pivotal Software. Another web platform is LAMP standing for Linux, Apache Web Server, MySQL database, PHP. A few other technologies is added to this mix to complete the web functionality that deals with the display of the initial page, the format of the display setting, security issues and other related topics.

One of the advantages of working with these platforms is that all these products follow similar standards which make the interface among these products similar and less problematic [14]. An interface between PHP and MySQL is less problematic that interface between Java and SQL Server for example. 


\section{JOB DEMAND AND TRENDS FOF WEB PROGRAMMING}

Donohue and Power [5] studied job titles in the information technology (IT) industry and noted that the abundance job titles in this field that stem from the abundance of IT technologies. This abundance of technologies created challenges for educators in the field as to what technology to focus on in their teaching. Smith and Ali [17] countered that and expressed that the best strategy to overcome this challenge is to monitor the market demand for IT jobs. Smith and Ali listed a number of advantages that can be gained from monitoring the job market by IT educators. The most relevant of these advantages are close the expectations gap and the employable skills. This section explains about these two factors in regard to IT jobs in general and to web programming jobs in particular.

\section{Close the Expectation Gap}

There is a general sense among various experts that a gap exists between the skills that IT job market demand and the training being offered at IT programs. This gap is explained in different studies. For example, a comprehensive study conducted by Gallivan, Truex and Kvansy [6] provides an analysis of the changing patterns for IT professionals. This study makes the following notes about IT education and what is offered at colleges and IT programs:

- The IT education is criticized as incapable of producing qualified employable professionals in the field.

- Universities teach obsolete or irrelevant technologies

- Academic programs are out of touch with the reality of the job market

- They neglect to provide skills that are on demand.

In regards to web programming, this gap can be more crucial as technology changes so rapidly and the teaching departments often may not be able to keep up with the rapid changes of technologies. In other words, most recent technological innovation will not be taught to the graduating students. Instead, students may be taught older content that do not respond to market demand. Monitoring the market demand and keeping an eye on what is being asked in the market is one way of closing this gap and to provide the students with the employable skills they need to enter the job market.

\section{Employable Skills}

Harris et al [9] conducted a study to assess the information systems job market in the 1970s and most recently. They reviewed job ads from careerberbuilder.com in five major cities Atlanta, Chicago, Los Angeles, Nashville and New York. The study found out that employers are asking for a longer list of skills in their ads. For example, in 1978/1979, employers were asking for an average of 2.63 skills per job ads. In 2010/2011, employers are asking an average of 7.54 skills per job ads. This explains the diversity and multi skills that employers are asking more recently. The difference shifted to include more focus on experience that required for employment in recent years. This places more demand on educators to update their curriculum in a way that integrates valuable experience in the field [12]. While this increase in skills per job is applicable to IT field in general, but the notion that this can be truer for web programming jobs. The number of technologies and sills required to learn web-programming jobs exceeds those of other IT jobs. Thus it is logical to assume that the skill required for web programming jobs is increasing as well.

Litecky, Arnett and Prabhakar [13] reviewed job search literature to see the different in requirements for soft skills versus hard skills. They came up with a two-stage model for IT recruiting where in the first stage, the technical (hard) skills are examined first and in the second phase, more employers examine soft skill as a condition for continuation of hiring.

Huang, Kvasny and Joshi [10] studied job advertisements in three sources: scholarly articles, practitioner literature and online job advertisements and to find the skills required in IT field. They found that scholarly articles lag specifics about the requirements in the job market. They also found that employers emphasize soft skill more while the online job ads specify more specific technical skills. Technical skills are most prevalent in the jobs that were advertised in online job ads. 
All the studies listed above indicate the need from IT professionals to understand the employable skills in this dynamic job market. The common notion is that understanding the job market brings benefits to the faculty teaching these courses - they can pass relevant knowledge to the students. Web programming and technologies is no exception to this as well. It will improve the chances of the students if they know the employable skills they need to have to help them compete in this dynamic and diverse web market.

\section{ASSESSING MARKET DEMAND for WEB PROGRAMMING LANGUAGES}

A faculty member at the department of Computer Science (COSC) at Indiana University of Pennsylvania (IUP) conducts periodic review of job market demand in the information technology field. This faculty has concentrated on programming jobs. He used a routine and a data mining technique to extract data from a job bulletin board on a regular basis over several years. A "Keyword Indexing" technique was employed to identify the number of jobs which list a specific programing languages or technology.

For this study the job site Dice.com was selected due to a focus on technical jobs, national audience, and being amenable to the web mining process. Since placed into operation in the 1990's, Dice.com has gained strong reputation as was rated the best job site by PC Magazine in 2008 [4]. Today around 80,000 technical jobs are posted for positions throughout the United States. Further information on the web mining process is given in our previous paper [17].

This procedure was used to gather data for years 2005 - 2007 and 2012 - present. Furthermore, specific technologies were added as the study progressed. While a gap exists, the results clearly provide picture of useful trends that can guide the curriculum decisions and content for web programming courses. The results specific to web languages and technologies follows.

Figure 1 provides the job tends of the dominate web platforms during the mid-2000's, that being .Net and J2EE. Skills in J2EE were in high demand in 2007 with near eighteen percent of all jobs in Dice.com referencing J2EE. .Net was a strong competitor with near fifteen percent. Both J2EE and .Net were garnishing a growing demand. In recent years demand for each has dropped, yet both still retain a significant job demand. .Net currently has a demand of ten percent of jobs in Dice.com. J2EE experienced a greater drop in demand and today has a job demand of seven percent. It should be noted that J2EE is a dated terminology that has since been replaced with Java EE. However, adoption of this term is not readily seen has the number of jobs in Dice.com reference Java EE is less than one percent. Not shown in figure 1 is the job demand for the LAMP platform. The job demand for LAMP is currently less than one percent.

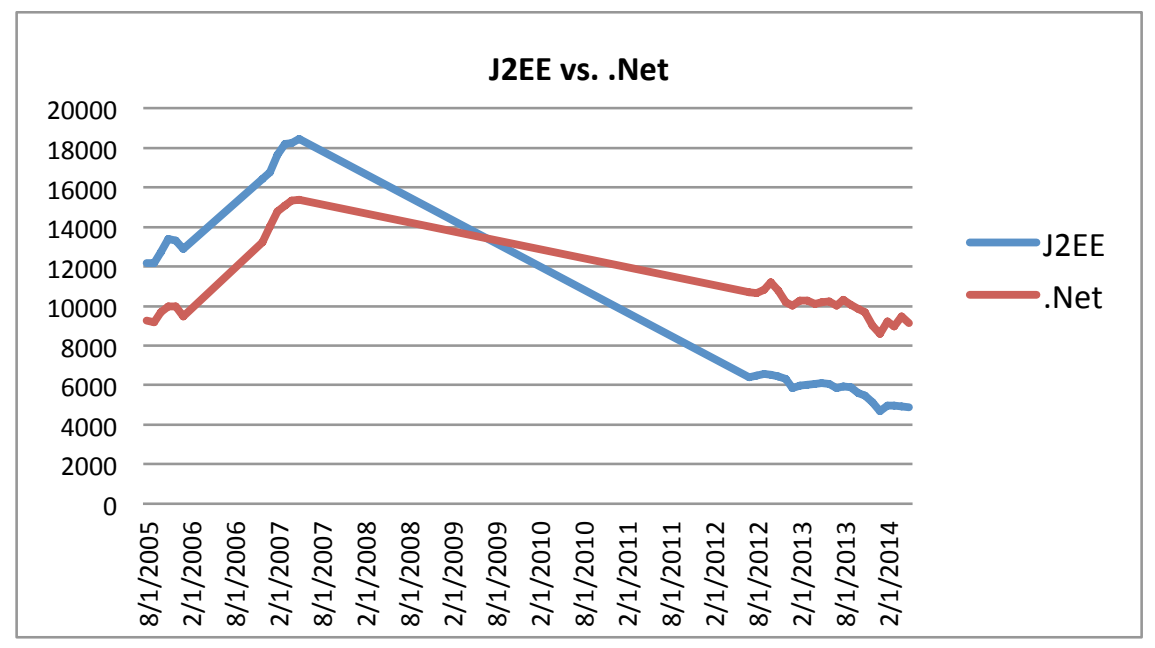

Figure 1: Job Trends of Web Platforms

Figure 2 below shows the job demand for programming languages. While these are general purpose programming languages, several of these are often used for components represent the business objects, or model, of a web 
application that are hosted on the web server. Java is the language of highest demand by industry. Near twenty percent of all technical positions in Dice.com reference Java as a desired skill. Searches using Java often identify jobs that are related to the web and identify web specific skills. C\# is a strong contender referenced by near ten percent of all Dice.com jobs. Like Java, searches identify jobs related to the web and web specific skills. While at one time Visual Basic and its lighter web specific version VBScript was fairly strong, the number of jobs has steadily declined. Python and Ruby on the other hand have shown steadily gains. Job searches using Python do identify web related jobs, but not to the degree of Java and C\#. In sharp contrast, nearly half of Ruby jobs were web related, specifically tied to Ruby on Rails.

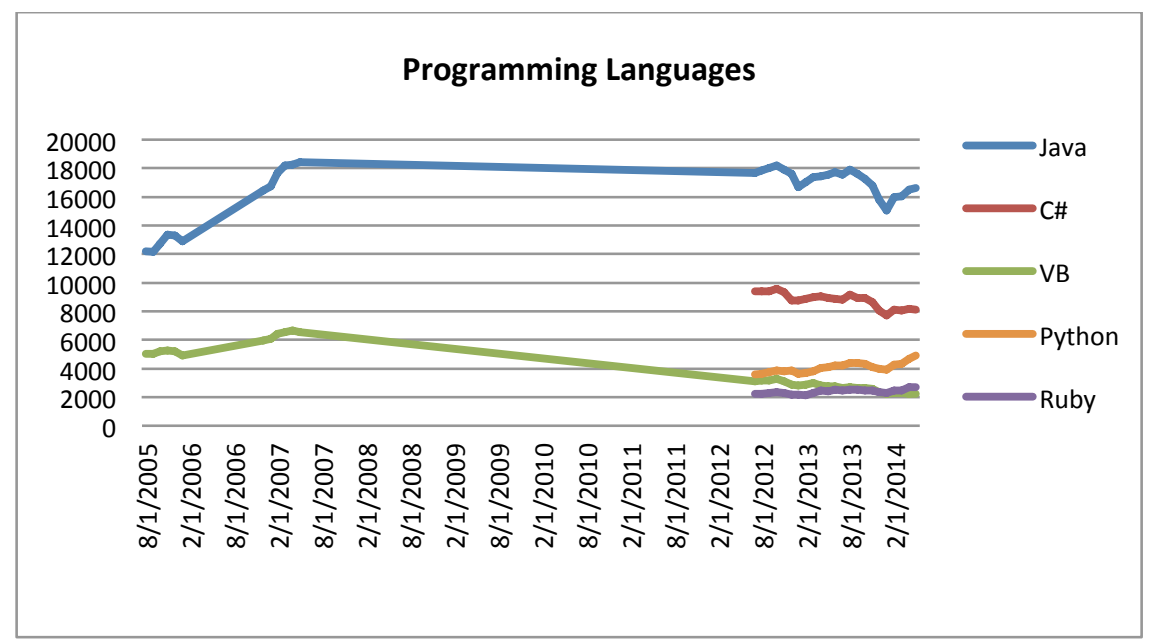

Figure 2: General Purpose Programming Languages used on the Web

HTML is a foundational technology of the web. The job demand for HTML, show in figure 3, clearly indicates that HTML is a skill in high demand. More than ten percent of all Dice jobs identify HTML. Of those a vast majority also identify CSS as skill in high demand. While a few percent less was found the demand for CSS, CSS tracks well with the demand for HTML. Noteworthy is the number of jobs that specifically identify HTML5 and CSS3, the latest versions of HTML and CSS respectively. The steady gain in demand for these specific versions indicates these are embraced by the industry and therefore skills with these specific versions are important. Not shown is the demand for XHTML and DHTML, predecessor of HTML5, since the demand was found to be below one percent of the jobs on Dice.com.

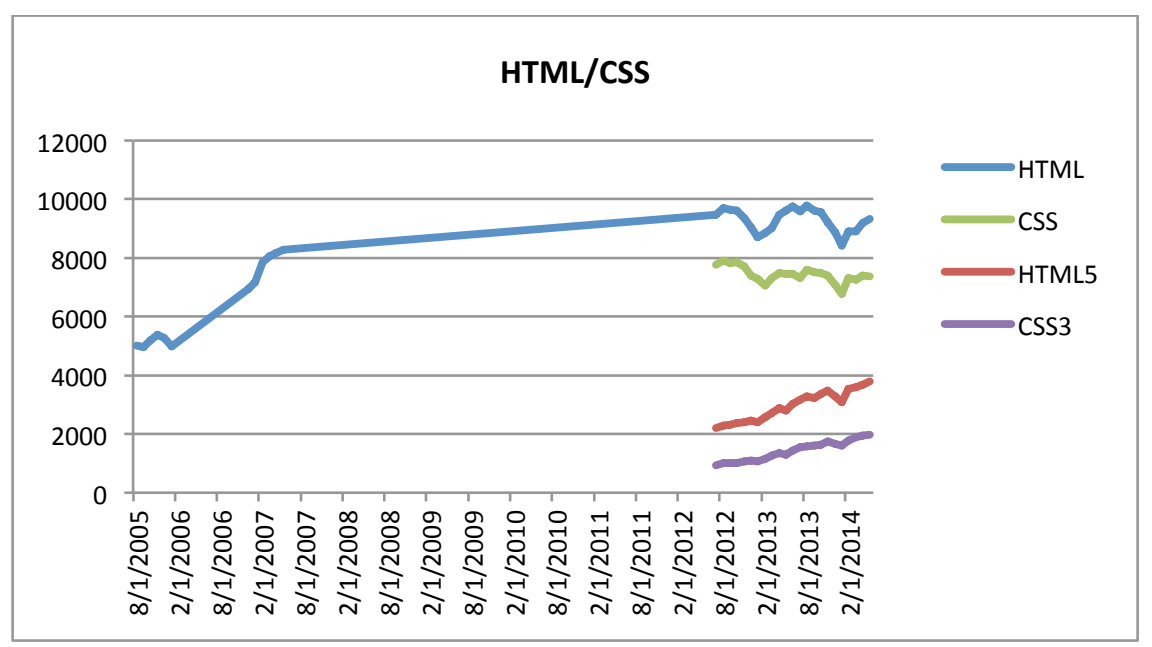

Figure 3: HTML and CSS 
A template service is used to insert data from business objects hosted in the web server into HTML for delivery and presentation on the Web browser. Specific to this task is Java Server Pages (JSP) and Active Server Pages (ASP). In addition PHP is a template service which includes its own server side language. Furthermore Rails of Ruby on Rails includes a template service. The job demand for these is shown in figure 4. While the demand for skills with ASP and JSP are significant, both have experience a steady decline. At the same time the demand for PHP has grown and surpassed that of JSP and is now around four percent of all jobs in Dice.com. While not as strong, Rails is showing gains in job demand.

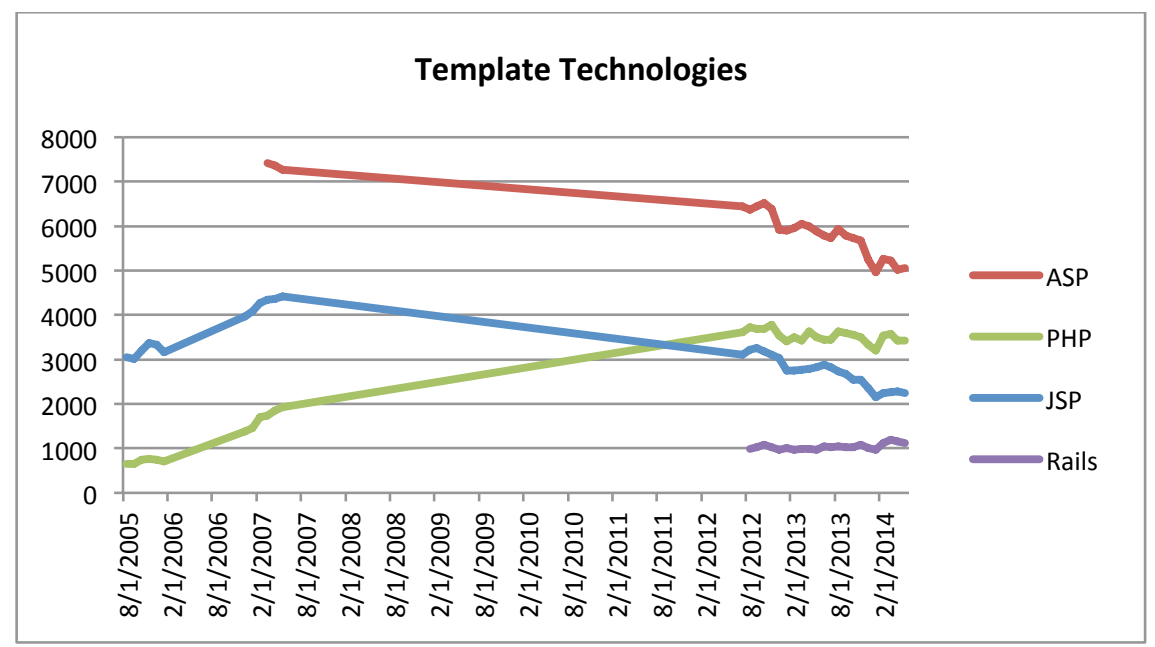

Figure 4: Template Technologies Job Trend

Providing an umbrella to manage the business objects, function as the controller, and utilize a template service is a framework. Frameworks facilitate development of web applications that can scale as requirements grow. Frameworks orchestrate the flow of a web application and include many rich features such as validation and internationalization. The job demands of several leading frameworks are shown in figure 5. Struts was a framework that was developed early. Initially, job demand was steadily growing. In recent years the job demand for Struts is on a steady decline. JFC was originally put forth as a competitor to Struts. While data for JFC was not collected until recent years, today's job demand for JFC (not shown) is below one percent of jobs in Dice.com. Rails, of Ruby on Rails, has gained demand passing the one percent mark. Replacing Struts and JSF is a newer framework Spring. Job demand for Spring is around five percent of all jobs in Dice.com. Yet to emerge above the one percent job demand are a number of PHP based frameworks including CakePHP, Zend, Symfony, and Django (not shown).

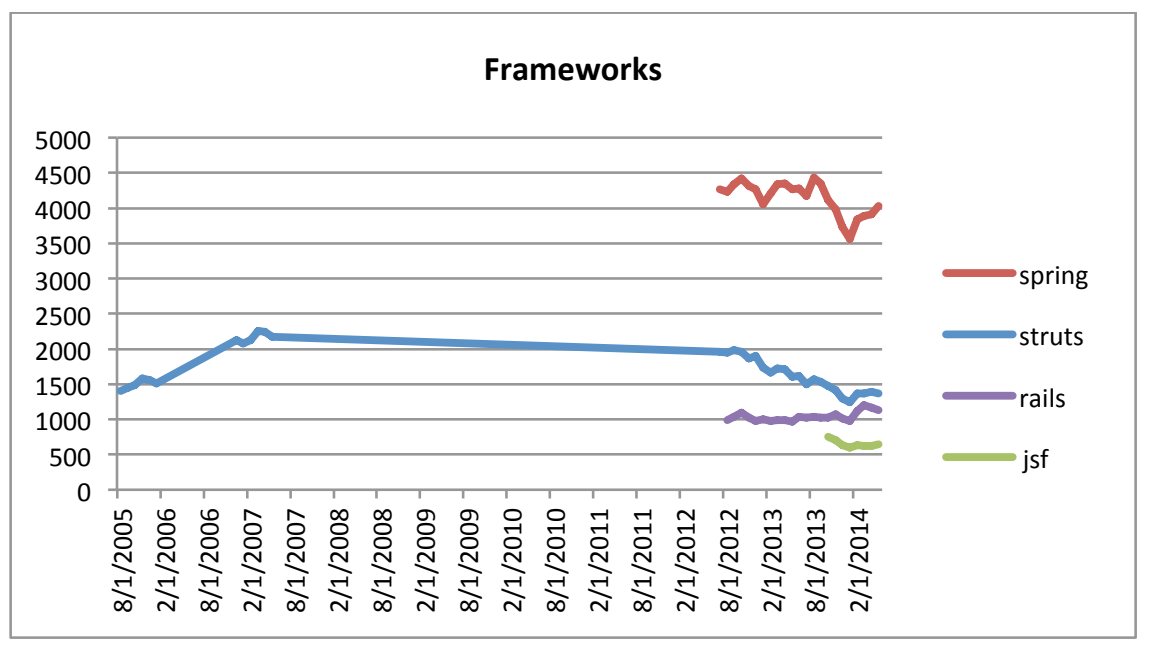

Figure 5: Frameworks 
Client side scripting has become a vital skill in the development of web applications as evident by the job market demand as shown in figure 6. Javascript has risen from about three percent of the jobs in dice.com in 2005 to near 15 percent today becoming placing second in demand of all programming languages. Javascript libaries promising to simplify the Javascript programing have emeged whereby a leading library jQuery is showing a job demand of seven to eight percent. Other Javascript libraries (not shown) including knockout, dojo, backbone and recently angular are emerging, but none of these have a job demand of one percent. A technology that augments Javascipt functionality is AJAX, which promises interactivity without interfering with the display of a web page. The job demand for AJAX is about five percent of all jobs on Dice.com

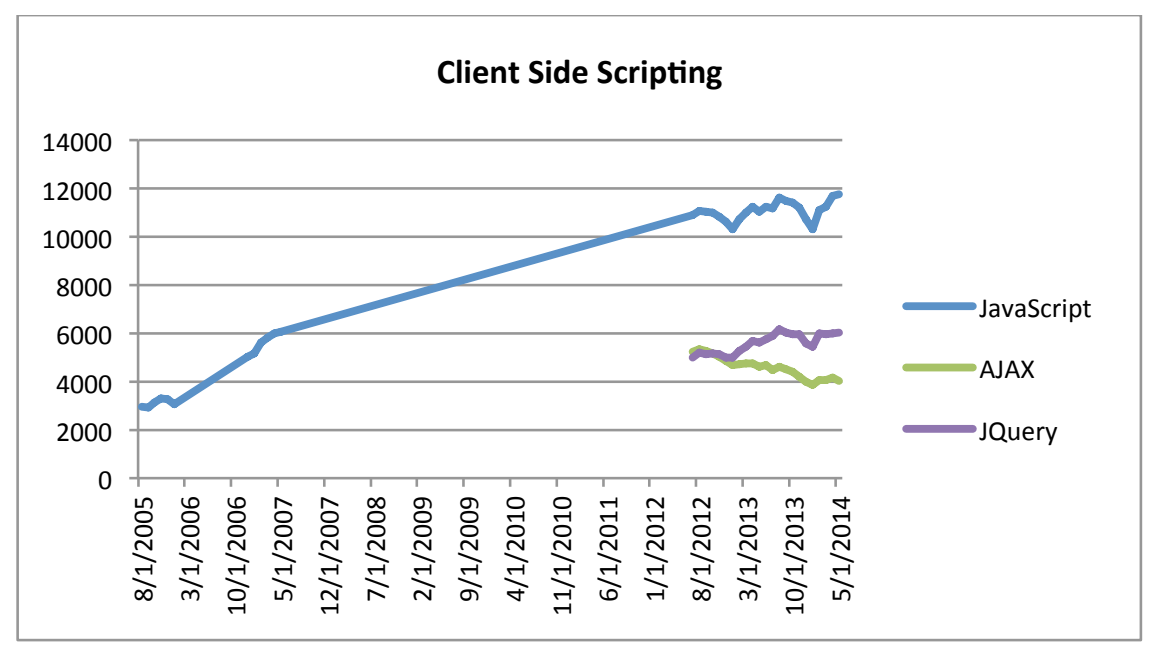

Figure 6: Client Side Scripting.

In addition to the languages and technologies shown in the preceding charts, data has been collected for a wide range of web related technologies include Pearl, Cold Fusion, Servlets, Java Beans, tags libraries, WSDL, SOAP, Rest, XML, XSLT, and XPath. Pearl and Cold Fusion is not reported here as the job demand for these is well below one percent. Others are not reported for the same reason. WSDL, SOAP, XML etc. is not reported here as these are related to web services that can be considered content of a subsequent course. We plan to report finding on these in a separate paper

\section{Impact on a Web Programming Course}

This study was initiated in 2005 with the main impetus to gather job demand data in order to shape the content covered in the Web Programming course taught at the Indiana University of Pennsylvania. In 2006 the technical focus of the course was on the J2EE collection of technologies augmented with a framework. As such, the content included Java (from a web development perspective), Servlets, JSP, tag libraries, and HTML. HTML was covered at the level needed to support dynamic web development with minimal coverage of polished presentation. Thus, coverage of CSS was light. Likewise, JavaScript was covered at a cursory level. J2EE was selected as this would leverage skills of Java gained in the CS core courses and at that time was the leading web platform. Struts was selected for the framework as it was an open source solution that was gaining demand, while at demand for JSF framework within J2EE had yet to show significant demand.

As a result of analysis of data collected herein several changes were made to content of the course. In 2013 a decision was made to provide greater emphasis of HTML, CSS, and JavaScript. HTML /CSS became a significant unit within the course with major coverage of HTML5 and CSS3. Skills in exploiting the presentation features were instilled. JavaScript too became a major unit within the course. Included in this unit is jQuery and AJAX, although these are at an introductory level. 
The next major change anticipated is to replace Struts with the Spring framework. The demand for Spring is strong while the demand for Struts in waning. While exposure to any framework will have its benefits, the time has come to make this change.

A curriculum dilemma is the growing job demand for PHP. Job demand for PHP has grown to four percent of all jobs in Dice.com and indications are that it will continue to grow. However, covering PHP and the LAMP web platform for the main focus of the course would ignore other major technologies. Still we may consider adding a unit on PHP and LAMP at towards the end of the course.

\section{CONCLUSION/RECOMMENDATIONS}

This study provided us with general information about the market demand for web programming and technologies. The literature review provided us with a snapshot of what is included in the teaching of a web-programming course at a computer science program. Based on the literature review and the analysis of data that we collected in this paper, we present the following recommendations regarding the content/technologies of our web-programming course:

- HTML and CSS presentation proficiency is in high demand. The demand for HTML5 and CSS3 is substantial indicating that these specific latest versions are embraced by the industry. Significant time needs to dedicate these within a web-programming course.

- JavaScript is an essential skill for the web developer, as such web programming courses need to provide coverage beyond a cursory level. Javascript libraries, such as jQuery need to be taken into consideration.

- Choice of web frameworks may vary, however it is important to keep assessing the job demand to insure curriculum is in line with market demands. For example, the Spring framework will be replacing Struts within our curriculum.

- The techniques presented herein are a valuable means for a department to continually access job demand in order to shape a curriculum, especially in an area of high dynamics such as web programing.

- PHP and LAMP present a dilemma. Focus on these may take away time from the dominate web programming technologies. However, job demand for PHP now and LAMP in the future may indicate that these be included in a web-programming course.

We are continuing to collect data on an ever increasing list of technologies on the web and beyond. For example, mobile development is on the rise with a number of competing technologies. Which ones will ultimately garnish an advantage is yet to be seen. Studies such as this will aide academia in preparing future software professional that are ready to contribute. We plan to present our findings in the near future.

\section{REFERENCES}

1. Ali, A, \& Mensch, S (2008). Issues and Challenges in Selecting Content for Web Design Courses, Issues in Informing Science and Information Technology 5, 209-231.

2. Bardzell, J. (2006). Macromedia Dreamweaver 8 with ASP, ColdFusion, and PHP, Training from the source. Berkley, CA: Macromedia Press.

3. Computer Science Curricula 2013 Curriculum Guidelines for Undergraduate Degree Programs in Computer Science. (CS2013) http://www.acm.org/education/CS2013-final-report.pdf.

4. DeLeo, J. L (January 22, 2008) 10 Sites to Help You Land a Tech Job. PC Magazine

5. Donohue, P., \& Power, N. (2012, May). Legacy job titles in IT: the search for clarity. In Proceedings of the 50th annual conference on Computers and People Research (pp. 5-10). ACM.

6. Gallivan, M., Truex III, D. P., \& Kvasny, L. (2002, May). An analysis of the changing demand patterns for information technology professionals. Proceedings of the 2002 ACM SIGCPR conference on Computer personnel research (pp. 1-13). ACM.

7. Gosselin, D. (2006). Web worrier series: PHP programming with MySQL. Boston: Course Technology.

8. Gupta, Pranshu, Ramon Mata-Toledo, and Morgan Monger. Utilizing ASP. NET MVC in web development courses. Journal of Computing Sciences in Colleges 27.3 (2012): 10-14.

9. Harris, A.H., Greer, T. H., Morris, S. A., \& Clark, W. J. (2012 Fall). Information System Job Market Late 1970'S-Early 2010'S. Journal of Computer Information Systems, $72-79$. 
10. Huang, H., Kvasny, L., Joshi, K. D., Trauth, E. M., \& Mahar, J. (2009, May). Synthesizing IT job skills identified in academic studies, practitioner publications and job ads. In Proceedings of the special interest group on management information system's 47th annual conference on Computer personnel research (pp. 121-128). ACM.

11. Holkner, Alex, \& James Harland. "Evaluating the dynamic behavior of Python applications." Proceedings of the Thirty-Second Australasian Conference on Computer Science-Volume 91. Australian Computer Society, Inc., 2009.

12. Litecky, C., Aken, A., Ahmad, A., \& Nelson, H. J. (2010). Mining for computing jobs. Software, IEEE Software 27(1), 78-85.

13. Litecky, C. R., Arnett, K. P., \& Prabhakar, B. (2004). The Paradox of Soft Skills versus Technical Skills in IS Hiring. Journal of Computer Information Systems, 45(1).

14. O'Reilly, T. (2006). What is ASP .NET. O'Reilly Windows Devcenter .Com. Retrieved August 20, 2007 from http://www.windowsdevcenter.com/

15. Serrano, M, Gallesion, E, Loitsch, F. HOP, A Language for Programming the Web 2.0. OOPSL

16. Sebestial, R. W. (2008). Programming the World Wide Web. Boston: Pearson Addison-Wesley.

17. Smith, David, and Ali, Azad. "Analyzing Computer Programming Job Trend Using Web Data Mining". Issues in Informing Science and Information Technology, 11 (2014) 203-214.

18. Stepp, Marty, Miller,J. \& Kirst, V. "A CS 1.5 introduction to web programming." ACM SIGCSE Bulletin. Vol. 41. No. 1. ACM, 2009.

19. Trent, Scott, et al. "Performance comparison of PHP and JSP as server-side scripting languages." Middleware 2008. Springer Berlin Heidelberg, 2008. 164-182.

20. Verbyla, J., \& Roberts, G. (1998). Web technology as curriculum. ACM Press. retrieved September 15, 2007 from ACM digital library http://www.acm.org/dl.

21. Wang, Xusheng. "A practical way to teach web programming in computer science." Journal of Computing Sciences in Colleges 22.1 (2006): 211-220.

22. Wang, X, McKim, J (2013). THE OPPORTUNITIES AND CHALLENGES TO TEACH WEB PROGRAMMING IN COMPUTER SCIENCE CURRICULUM CS2013. Consortium of Computing Science in Colleges , 67-78.

23. Wang, Xusheng. DESIGN, DEVELOP AND TEACH THE SECOND WEB PROGRAMMING COURSE IN COMPUTER SCIENCE CURRICULUM, Consortium for Computer Science in colleges, 2014. 